\title{
Multilingual and transnational encounters in late modernity: Linguistic practices and social processes
}

\author{
Luisa Martín Rojo and Rosina Márquez Reiter
}

\section{Globalisation and the service sector}

New economies represent an ongoing evolution from industrialisation to informationalisation (Castells 2000). This is evidenced by the transition from industrialbased to service-sector based economies. The informationalisation of both the private and the public sectors is a fact that we, as human beings, have to deal with in our daily lives. A case in point is the pervasive nature of call centres in both developed and developing economies and the rapid growth of computer-mediated government services in some developed nations (e.g. enabling a tourist visa to be obtained using the internet). The tertiary sector of the economy, also known as the service sector or the service industry, currently plays a central role in the new economies, and language is a much more significant factor there than in the primary sector (e.g. agriculture and fishing) or the secondary sector (e.g. manufacturing) (Duchêne and Heller in progress).

While language and communication are important elements of all the sectors of the economy, they play an essential role in the provision of services to facilitate interchanges between persons of different origins and communicative practices in order to enable not just the performance of these activities, but also to make it possible for the participants, who may not share cultural assumptions or values, to (re)negotiate their relations and identities. Language and communication are also important in the localisation or adaptation of transnational services and companies to the local reality of markets, customers and their needs. The labelling and instructions that accompany products, such as computer software, and that appear in advertising constitute examples not only of how translation into various languages is required, but also of the fact that localisation to the immediate environment depend on the language (services) to be realised. From place to place, the differences in the content and the information considered relevant are considerable.

The picture that emerges is two-sided. On the one hand, multinational firms from developed economies rebrand themselves to fit in with linguistically different new economic markets (e.g. Telefonica rather than Telefónica in Europe), yet on the other hand, they do so with minimum expenditure, by seeking standardisation in an effort to avoid formulating differences in procedures which fit with local expectations (e.g. the inhouse rules for opening calls in the call centre examined in this volume by Márquez Reiter). For their part, developing economies, such as those in Latin America, engage in active negotiation with the developed world (e.g. the EU and the USA) in the hope of placing products in their highly regulated economies and securing foreign investment in order to create jobs. 


\section{Service encounters in new socioeconomic landscapes}

It is well-known that capital, production, management, the markets, the labour force, information and technology are all organised in this global era via flows that cut across national borders, and that this, in turn, requires a parallel modification in communicative practices on the local level. These changes in communicative practices and in linguistic landscapes (e.g. relatively recent immigration from non-EU countries to Spain) have made these new communicative environments priority areas of study for the sociolinguist. A large proportion of the studies included in this volume, which also focus on new linguistic landscapes, can be classified within one of the current trends of 'sociolinguistics of mobility’ or 'sociolinguistics of globalisation' (Blommaert 2003). Among the phenomena remarked upon in this literature is the commodification of languages and the increase in multiculturalism in intercultural encounters (e.g. Heller 2003), both in the provision of services in transnational environments (e.g. call centres) and in ever-more diverse domestic ones (e.g. access to health services and education).

The domains in which intercultural transactions take place are expanding. Not only do we find them at call centres, but also at legal advice centres, services for migrant workers and asylum seekers, government offices and public-private partnerships both in Spain and in Latin America. In Spain, the evolving multilingualism in encounters is taking place within a context of change where the isolation suffered during the era of General Franco has been broken. A formerly rigid social order has been made more flexible, in part as a result of the achievement of universal education. Centralist monolingualism has given way to the recognition of co-official status to the regional languages. And the assimilationist models of integration aimed at ethnic minorities have been called into question.

Spain, an emerging new economy and net receiver of migrant workers, is now floating in a global current and investing in new forms of colonialism in order to play a significant role in the broader European context. For over two decades, Spanish-owned companies have done a great deal of business in Latin America in an effort to protect themselves against Spain's economic slowdown (e.g. BBVA, Endesa, Iberdrola, Repsol, Santander, Telefónica). This effort can be described as a déjà vu of Spain's colonial past: the search for gold is now a search for 'silver' (i.e. in Latin American Spanish 'plata' literally translates as 'silver' but is also generally used to mean 'money'). Under the discourse of cultural affinity and a shared language, from 1993-2000 Spanish firms invested on average $\$ 9.7$ billion per annum, principally in the biggest economies of the Southern Cone (i.e. Argentina, Brazil, Chile) (The Economist, 30 April 2009). Despite economic crises in the region (e.g. 'El Corralito' in Argentina, when bank accounts were frozen for a year) and the upsurge of socialist governments, Spanish investment in Latin America has grown. Spain now constitutes one of the largest foreign investors in this region, with Telefónica at the forefront.

The way in which the new economies are managed by the multinational firms of the developed world is reminiscent of colonial times. The analogy with colonial times is all the more relevant when we consider, among other things, the struggle between former and current (neo)colonial powers for economic supremacy in the region. For example, in Argentina's telecommunications market, we find Telco (a former power) fighting to hold on to their former monopoly as Telefónica (a newer company) gains more ground. We also find old colonial powers in pursuit of new riches: Spain's Telefónica and Portugal's Telecom seeking expansion in the Brazilian mobile telephone market. Further evidence of 
these states of affairs in the telecommunication industry is the recent EU motion to bring down mobile phone charges and thus regulate rates within the EU for the benefit of consumers and, by contrast, the exorbitant cost of calls in Latin America charged by the very same companies. It is in this sense that a process of commodification of Spanish language can be seen; the language itself has become an economic resource in channelling commercial exchanges across continents.

But, to understand commodification and the role of language(s) in this process, we must move beyond Spain to examine the phenomenon in other places in the world, especially Latin America. The fact that countries in Latin America, marked by a history of colonisation, respond differently to the expansion of transnational markets in general, and Spain's efforts to play an increasingly prominent role in Europe and in the world, presents us with a mosaic in which a single language may take widely varying roles, have different statuses and coexist in different ways with other languages. New communicative contexts emerging from new migration and old colonialism have yet to be thoroughly explored in Spain and Latin America, unlike in other regions. This situation, in the case of Spain, is partly the result of the ways in which the Franco dictatorship imposed political centralisation and monolingualism, censured and silenced social conflict and forced linguists to work in isolation. With the re-establishment of democracy in 1977, sociolinguistics emerged most prominently in (officially) bilingual regions of the country. However, certain topics of research have remained untouched, such as the linguistic varieties of ethnic minorities and of the working class. Furthermore, the study of immigration-related multilingualism encounters open resistance. Likewise, research into the contact between native speakers of different varieties of Spanish who, due to geographical and political divisions that partly date back to colonial times, rarely communicate with one another despite being brought together as a result of the new economies is a modern phenomenon which has yet to receive attention.

As demonstrated in the essays of this issue, the value assigned to languages in the new economies varies according to the setting, participants and the domain of use: Gómez's paper demonstrates a preference for English in asylum interviews, Moyer's paper shows us how in call shops owned by migrants, local languages are freely interwoven by shopkeepers and clients, quite unlike the constrained and regulated talk present in the Administration or NGO offices. This new socioeconomic landscape reflects a persistence of colonial ideologies; the new linguistic practices associated with transnational markets also reflect the survival of a colonial framework. This can be seen in the institutional representative's and service-seeker's preference for English and Spanish in services provided by the Catalan administration, by the deployment of English rather than Spanish at asylum interviews in Madrid and by the call centre's effort to regulate talk. Such regulation is partly the result of the perceived linguistic homogeneity and cultural sameness of the various Latin American nations, due, no doubt, to many of them sharing a common language, presumed to be equivalent to the Northern variety of Spanish spoken on the Iberian peninsula, which is prescriptively taught across Latin America and thus is somewhat familiar, although not embraced, by those so educated. The rules and grammar of standard Northern Peninsular Spanish are given precedence over the various local Latin American varieties of Spanish spoken in the continent. They represent rather arcane language practices by those who are forced to use them, at least in the initial stages of the 
talk. Arcane as they may be, they are used to judge the appropriateness of talk in a modern societal context (i.e. mediated and centralised service encounters).

New colonial ambitions give rise to new contexts of multicultural exchanges where participants bring different expectations. The articles in this monograph contribute to an elucidation of participant goals and expectations by examining linguistic practices in some of these newly created institutional spaces in the service sector, particularly in settings where Spanish has a role to play. The articles show that the services provided, the contexts in which this is done and the institutional framework are not identical in every case.

The studies seek to understand how institutionality is constructed using data from multilingual and Spanish talk. In this sense, the papers build upon, Drew and Heritage's (1992) unanimously accepted observations that, in constructing talk, participants have an institutional purpose in mind that shapes the interaction. Their goals are institution-specific and there are restrictions on the nature of the contributions they make. Additionally, there are institution and activity-specific inferential frameworks at play and the allocation of turns is different from that observed in ordinary talk.

The various ways in which institutional talk is constructed in these articles reveals the great diversity of institutional frameworks to be found in the environment of service provision and in the different regimes governing it. These differences are constructed and modulated, to a greater or lesser extent, in linguistic practices (e.g. in the choice of languages, in the way participants orient to face concerns, in conversational dynamics, in the participation frame, and so on). The analyses show, on the one hand, that the differences recorded in social practices, depending on whether they concern public, private or public-private service-providers, create a global level of framing, which affects how the participants view the purpose and nature of the exchange and what mutual rights and obligations apply, what topics can be brought up, what is expected by way of a reply, as well as what can be put into words and what is to be implied. The analyses also show that participants' mobilise their linguistic resources to (re)construct different relations and meanings within these varying institutional settings.

Thus, we have examples in the public system where services provided as a result of migratory flows may be directed exclusively at the immigrant population, or simultaneously at both the latter and the local population. Communication in these settings is both multilingual and multicultural. As Codó and Garrido, and Moyer note, the provision of basic services such as health, communication, legal advice and social benefits for new citizens are being offloaded by the nation-state and placed in the hands of private corporations and volunteer-based NGOs, which pursue private economic interests or ideologically motivated missions. Public institutions are simultaneously adopting neoliberal management strategies where accountability and cost-benefit calculations have become a criterion for reducing public services. In this respect, Codó and Garrido examine the externalisation of a service that had been delegated to an NGO, with a strange regime in which the boundaries between the private and the public sphere became rather blurred. Taking a contrastive viewpoint, the authors look at linguistic practices in a legal advice service, provided on the one hand by a migrant support organisation, through which migrant workers are informed about the different bureaucratic procedures connected with their legal status and applications for some of these procedures are submitted on their behalf. On the other hand, the state immigration office no longer offers general information on legal issues, but rather handles different types of requests (work permits, 
card renewals, bringing family members still in other countries to Spain, etc.) submitted by individual migrant workers themselves or through support organisations. Differences in social and linguistic practices, depending on whether they concern public, private or public-private service-providers, are revealed by Moyer's analysis of the management of multilingualism in three institutional contexts in and around Barcelona, Spain: a local call shop , a public health clinic and the local office of an international NGO located in the Barcelona metropolitan area.

In the case of the tourism sector, the provision of services is discussed with respect to both face-to-face and mediated environments (Moyer and Márquez Reiter papers respectively). In face-to-face service encounters, communication between the participants is multilingual and multicultural (Catalan, Castilian Spanish and English), whereas mediated settings deal with monolingual (i.e. Spanish), albeit intercultural communication in the sense that the participants come from different cultural backgrounds in Latin America. Multilingual communication is examined by Prego in the context of a relatively new local government economic venture: a public-private partnership (PPP) responsible for providing electricity to a local community. The case of the PPP shows how different relationships are co-constructed through given discursive practices. Upon the local government's decision to change the standard model of public procurement, new relationships are being negotiated between the service provider and the service seekerfrom consumer to client-and, in turn, from civil servant/public employee to private employee.

Thus, there is a variety of ways in which institutional talk is constructed as evidenced by the way in which the relationships among participants are constructed and by the way in which the participants (re)position themselves within their pre-assigned roles of clientsupplier, user-supplier, volunteers and service seekers, officials and applicants. The forms of talk observed, though institutional in that they are primarily oriented towards to the pursuit of an institutional goal, range in degrees of formality, both in terms of the linguistic resources employed (e.g. T/V, switches between the language normally associated with institutional domains-Spanish-and the language historically associated with the domestic domain-Galician) and also in the way the conversation is structured (e.g. allocation of turns). Participants thus create different contexts and interpretation frameworks, switching between formal and informal modes to construct other types of relations in the pursuit of their (differing and sometimes almost opposite) institutional goals. In almost every case analysed, parties are allowed to depart from the institutional interactional format and resort to ordinary conversation. In Márquez Reiter's and Prego's papers we can see how participants manage the sales pitch by mobilising resources reminiscent of ordinary talk and how these resources, in turn, help to personalise the interaction in an effort to obtain an institutional goal and pursue a specific institutional agenda. To this end, they employ devices such as 'small talk' (see Márquez Reiter's in this issue) and code-switching (and Prego's in this issue), making the type of talk analysed quasi-institutional talk (see Arminen 2005). The analyses, thus, illustrate the complexity and the multi-directionality of the relations between linguistic and social practices, the different inferential frameworks of the various modern institutional environments examined (public, private, PPP) and the participants' management of this complex web.

In these new contexts, the literature focussed on the significance of the national or transnational environment in which the service was provided. But this factor has become 
less important to sociolinguists since today both environments are characterised by a high degree of linguistic diversity. Rather, attention has been aimed toward the impact that the public-private ownership of companies, migrated call centres and so on have on the interaction. To this end, the articles of this volume contribute much to our understanding that despite the changing voices of an ever-increasing multicultural clientele, some public institutions overlook communication related matters, assuming Spanish to be the natural and logical language of interaction. The natural and logical language of interaction between speakers of different languages and language varieties may bring potential interactional asymmetries and these asymmetries, in turn, are aggravated by corporate efforts to ignore cultural differences in the pursuit of profit.

\section{The management of multilingualism}

In this section, we discuss the sociolinguistic order (Martín Rojo 1997, 2001) ${ }^{1}$ that emerges in the institutional encounters analysed by the authors in this issue: that is, what we may conclude about which linguistic varieties can be used, within a given social field ${ }^{2}$ (i.e. institutions), when and by whom.

Multilingualism is now pervasive in Spain, and it encompasses the national state language (Castilian Spanish), both its local varieties and the 'standard' imposed by multinational forces, the co-official languages in some autonomous regions (Catalan, Basque and Galician) and the languages of migration (Urdu, Dariya, Latin American varieties of Spanish, etc.). However, in spite of this increasing multilingualism, monolingual ideology of 'one state - one language' is maintained. Thus, the sociolinguistic order revealed in the studies of this issue demonstrates that Spain's national language is maintained as a key element in the construction of the nation-state's ideological discourse. What usually underlies officially monolingual and bilingual nationstates is the assumption of a one-to-one relation between language and its group of speakers (Billig 1995). ${ }^{3}$ Behind this search for a linguistic unity lies a political assumption, still very much in force, namely, the idea that speaking only one language would provide cohesion to the State. Certainly, this assumption only applies to nationalities which have to struggle to be recognized and face a process of decolonization, although that can produce a mirroring effect over other minorities. There is also a second supposition, of social and egalitarian nature, prevailing nowadays in the centralist region of Madrid: the belief that the existence of a common (dominant) language will help citizens gain access to certain social spheres, such as the school or the parliament, from which some social groups had been traditionally excluded (working classes, ethnic minorities, etc). Until a few decades back, both ideas contributed to the homogenising treatment applied to diversity.

In the case of Spain, language practices in service encounters follow the monolingual formulations of the nation-state that affirm that Castilian is the official language of the State (Spanish Constitution, Article 3). This is reinforced by the Spanish Constitution of 1979, which affirms that 'all Spaniards have the duty to know and the right to use Spanish'. This has historically been applied to linguistic minorities in Spain and is now contributing to the imposition of linguistic homogeneity in multilingual settings.

These nation-state ideologies of monolingualism and citizenship are particularly unchallenged in the traditionally monolingual region of Madrid, where Castilian is the (sole) language used in service provision. The papers collected in this issue show the extent to which the Spanish language is the only legitimised language of exchange in these 
encounters and how its use is clearly bound to national discourses about citizenship (see also Martín Rojo 2010, Moreno Cabrera 2008).

In the case of Catalonia, the Basque Country and Galicia, Spain's legislation formally establishes Spanish and the corresponding national-regional language as co-official languages, but most internal activities (i.e. meetings, written documents, interactional exchanges and brochures) of the Catalan public administration are actually produced in Catalan. The construction of the nationality is also, in this case, inextricably bound to the use of the co-official language. Thus, in these autonomous communities, although multilingual practices are familiar to speakers, and in spite of a relatively prevalent positive attitude to diversity, a dissimilar valuation of linguistic 'national' and 'migrants' varieties is pervasive. In fact, in Catalonia, Catalan embodies national identity, and it is a cultural capital that ensures access to networks of power and employment (Pujolar 2007). Nevertheless, this language is not used with or demanded of migrant workers, in part because, traditionally, Catalonia received Spanish-speaking migrants from other regions of Spain, who at least in early times did not always back the Catalan national project. Spanish is the language of exchange with migrant workers, refugees and asylum seekers but is not the dominant language of the Administration. In this way, the full access to the provision of services and to integration into the society as a whole is also questioned.

The situation of Galicia and the valuation of Galician seem to be more complex. A pejorative attitude towards Galician is reflected in the lack of legitimisation of this language in institutional encounters. Analyses of interactions likewise reveal it to be a language whose use seems not to be legitimised in this context. In Galicia, although bilingual practices are rather usual, the norm is still monolingual.

In spite of this maintenance of a monolingual ideology of 'one state - one language' in the Spanish State and to some extent also in Catalonia, evidence can be found that illustrates how it is, in fact, being increasingly eroded. The contributors to this issue show how changes in the economy and the commodification of language (Heller 2002, 2003) are transforming the univocal relationship between one-nation and one-language. Companies are discovering the economic benefits of embracing the language of the majority or minority groups. At the same time, the use of English as a global world language (and to a lesser extent, former imperial languages such as French and Spanish) by post-colonial societies, supra-national organisations and in communications technologies, also calls into question the monolingual language practices of nation-states. Migrant workers, refugees and asylum seekers are the new social actors challenging the hegemonic linguistic construction of the nation-state from below in different ways (see Moyer and Martín Rojo 2007).

In this context, tensions between the reproduction of a monolingual ideology of 'one state - one language' and the actual multilingual practices inevitably arise and take different forms as illustrated by all the papers in this issue. Ideological contradictions are too often observed, making the unravelling of these new linguistic landscapes a challenge.

Thus, even in the services created to inform and assist migrant workers, refugees and asylum seekers, tokenistic multilingual initiatives rather than a global institutional approach to multilingualism are found (see Codó and Garrido in this issue). As regards the use of local languages and those of migrants, although the linguistic repertoires of the participants do not coincide, and although different languages co-exist, the linguistic norms that are reflected and constructed in the interactions analysed reveal clear 
impediments to a truly multilingual order. For example, despite the presence at the MSO in Codó and Garrido's study of an advisor fluent in four languages (Wolof, Pula, Sose and French) who was also familiar with Arabic, English, Spanish and Catalan, all in-house services were accessed via a monolingual (Spanish) Latin American receptionist.

Services were not always adapted to their users' linguistic needs. The only time that the administration and organisations did partially adapt to user and client linguistic needs was in using English, a language of prestige - and also a State language - which was used as a lingua franca. The case of Catalonia seems to be paradigmatic. Increasing linguistic diversity is challenging the way Catalan and Spanish have traditionally been negotiated in institutional spaces. Governmental efforts to promote the use of Catalan among newcomers have not always been put into practice by the various institutional sites analysed (e.g. the fact that SAUME opted to teach of Spanish rather than Catalan to newcomers). This choice seems to be related not only to the need of reviewing the relationship between the language and the national project, but also shows a distribution of language linked to a progressive ethnic stratification of the job market and of society as a whole (García Borrego 2007; see also Martín Rojo 2010).

Other evidence of a lack of adaptation to users' needs can be found, as in the institutionalised lack of interest in language matters at the locations documented in all the papers in this issue. Language-related questions are rarely explicitly addressed in staff meetings or employee seminars. Communication, especially in connection with information provision, is hardly ever problematised; institutions seem oblivious to the complexity of communicating with a highly heterogeneous clientele and seem to take for granted that their service providers will be able to do so.

This lack of adaptation can be seen as part of an ethnocentric approach corresponding to the values of the host community. As a consequence of it, linguistic matters are not considered significant, resources, like interpreters and translation services, are not always provided, although volunteer work is sometimes accepted (see Moyer, Garrido and Codó, and Gómez in this issue). And something similar happens with linguistic prejudices and ideologies. Besides the monolingual ideology of 'one state - one language', a standard language ideology is ethnocentrically maintained in the ways in which languages are managed. For example, select migrant languages are legitmated, while certain of their varieties are opposed (for example, standard Arabic may be utlized rather than Darija, the Moroccan variant); the written mode is imposed (over oral mode) which, in turn, privileges translation over interpretation (and preference given to a Castilian standard rather than to any other variety of Spanish) (for a deeper analysis of these impositions see Moyer forthcoming). These linguistic choices, which are presented as strategies to facilitate comprehension and integration, reflect the values of the majority and not those of minorities, which are marginalised. Similar remarks apply to cases in which communication must take place through the mediation of interpreters, other intermediaries and via the translation of documents. It is the institution, not the users, that decides whether interpreters shall or shall not be made available, that also decides what needs to be translated and what does not and in what language variety this should be done. Given the circumstances and the explicit institutional encouragement, those users who are not competent in Spanish often rely on 'ad hoc interpreters’ (Bührig and Meyer 2004).

Ethnocentrism is also percetible in the way in which linguistic mediation is realised by one asylum interpreter who does not grant importance to the ethnic dimension of the 
political conflict that affected an asylum applicant; the interpreter thus discards this information, which, consequently, weakens the legal basis for the asylum request (see Gómez's article in this issue).

We can conclude that institutions fail to recognize the great diversity present, and that even when institutional representatives appear to be accommodating, they are really just patronizing (see Codó and Garrido), infantilizing (see Moyer as well as Prego) or subjugating their interlocutor (see Moyer), or else leaving unrendered, effectively erasing, aspects of the client's personal history that do not fit into their own worldview (see Gómez). This failure seems to be related to the maintenance of two previous and welldocumented linguistic ideologies, the one language-one state ideology and the standardlanguage ideology. Such a sociolinguistic order, as we have seen, shapes interactions and constructs and reinforces social asymmetries, with institutional actors playing the role of gate-keeper.As a mirror image, Latin America shows the persistence of a monolingual and colonial order, where certain local Spanish varieties are dominant and other American language are completely excluded from service encounters (see Márquez Reiter in this issue). While a monolingual order persists, there is also multidialectism in service provision. This contrasts with the multilingualism that presides over exchanges in Spain, the former metropolis, and the ensuing tensions it rouses. The question is posed: how do participants acquire the necessary skills to interact in a heterodialectal world? The fact that communication in transnational services obliges speakers to familiarise themselves with diverse practices has enabled us to examine how these practices are managed and whether interdialectal forms are emerging.

Companies choose certain communicative patterns over others and, in attempting to regulate the way in which institutional agents handle clients, they pursue the projection of a particular professional persona. This commercial identity stems from the companies' perception that the standardization of services across the world is a recipe for success, that the written word trumps spoken language in value and that essentially North American (i.e. US, Mexico) business practices are superior to others. However, as Márquez Reiter's paper shows, this projected identity does not sit well with the cultural background (linguistic, educational) of some of the agents who, in practice, challenge aspects of the linguistic practices recommended by their institution's in-house rules by (inadvertently) violating them. The flouting of the in-house rules is, however, ethnocentrically/locally interpreted as a violation of social norms by the client, as illustrated by the occurrence of metapragmatic comments, and brings to the fore power differences between the participants. Thus, it reflects the essentially asymmetrical nature of the interaction despite the relatively high incidence of conversational footings (Goffman 1979) instantiated in this institutional environment by the agent to counterbalance such imbalance. Thus, the management of linguistic resources in mediated, transnational, intercultural encounters in the private sector, in contrast to the saying in commerce that the customer is always right, shows also little adaptation towards the user. Here, too, the supplier reveals elements of ethnocentrism, such as the use of small talk as a sales strategy, which, although it does evoke a relation of interpersonal connectedness (Fitch 1991), at the same time creates the feeling among some customers that a respectful distance (Márquez Reiter and Placencia 2004) should be observed, that they are wasting their time or that the interchange in question is not a relevant one. 
The analyses of linguistic practices reveal the active involvement of social agents (suppliers and users) and how they can act upon the reproduction of the sociolinguistic order (being monolingual and adopting Castilian standard, for instance), but also in its challenging (demanding the use of other languages or an interpreter's assistance). Suppliers reinforce a linguistic order that is founded upon their own linguistic ideologies and on their evaluation of different languages. Users, on the other hand, sometimes challenge this order by deploying languages that are not considered legitimate languages of exchange. Speakers challenge this sociolinguistic order and look for other ways of managing multilingualism, as Moyer shows in her examination of the call shop run and used by immigrants. In this case, non-standard varieties are utilized, code-switching of a variety of different languages and a structurally simplified Spanish is used as a lingua franca in face-to-face communication. These linguistic choices contrast with the homogeneous standard language offered to customers by major telecommunication companies.

Similarly, the prevalent valuation of linguistic resources is built and negotiated through interactions. Independently of whether or not a language is shared, participants did not attribute the same value to linguistic resources and to interactional processes. Two cases in point are illustrated by the use of code-switching in Prego Vázquez's paper and by the metapragmatic comments examined in Márquez Reiter's article. In the former the use of Galician, analysed by the author in terms of a contextualisation cue (Gumperz 1982a) is interpreted differently by the participants. While it shows an asymmetrical relationship between participants in which one of them adopts a didactic role, he thus so in Galician, the language of the community, the language that is normally employed in every day encounters. In the latter, a switch between the formal to the informal register is made relevant as unexpected and inappropriate communicative behaviour by the client. In both papers service providers mobilise ingroup languages and informal style to personalise the interaction in order to obtain an institutional goal.

The agent role of speakers in challenging the sociolinguistic order and the prevalent valuation of languages illuminates the dynamics between structure and action, and between the reproduction and transformation of the sociolinguistic order. Linguistic and communicative competence is revealed as socially shaped and assessed. Depending on whether a skill is displayed during the interaction, which is always measured according to the standards set by the majority, speakers are seen as more or less legitimate participants. In the analyses presented, it can be seen that the question of competence plays an important role, and is linked to social categorisation. In the institutions studied by Codó and Garrido, multilingual competences are constructed as exceptional. Lack of competence in Spanish becomes a linguistic barrier for newcomers to access, for example, the free legal advice service provided by the immigrant support organisation. It may even occur that participants compete for access to the latter on the basis of their knowledge of a foreign language, like English (i.e. the language used by institution's representative) or a second language, such as a colonial language to which those who are educated have access in the applicant's and interpreter's respective countries of origin. At the immigration office, this language is spoken mostly by South Asian migrants who seek precise information about the status of their applications for legal status. In spite of the generalised low competence levels among the office staff, South Asian service seekers are habitually constructed as having limited skills and even as trying to deceive public servants by 
pretending to speak English while in fact they do not (Codó 2008). Equivalent examples have been analysed by Martín Rojo (2010), with respect to speakers of Latin American varieties of Spanish.

A common denominator in the situations examined in this issue is the lack of adaptation to multicultural communication where a perceived linguistic homogeneity is apparent at both national and transnational levels and reinforced by the way in which services are provided. Furthemore, evidence of this lack of adaptation is also provided by the fact that the staff in the administration services and in NGOs were not required to know foreign languages when they were employed, nor were they told that they would need to speak languages other than the two local ones to carry out their work duties. The given asymmetry that dominates relations (i.e. client-agent, consumer-utility provider) is (re)constructed by the type of activity, by the languages employed, by the valuation of languages, and by the perceived status of the participants. It is also influenced by the multicultural experience and the command of languages possessed by each of the participants. The management of linguistic resources reinforces, naturalises and, on occasion, challenges this (given) asymmetry.

\section{Concluding remarks}

The five articles of this special issue all share a commitment to the analysis of discourse, understood in a broad sense, and, importantly, to the examination of discourse in late modernity and in contexts of multilingualism. This is done by focusing on contemporary socio-discursive fields in some of the nations that form part of the Spanish state and by examining the role that Spanish as a colonial language still plays in Europe and Latin America. The authors examined institutional discourse in contemporary environments (i.e. immigration and tourism in Catalonia, government offices, call centres in developing economies, etc.). In their analyses of the interactional patterns in contemporary communicative contexts, the authors have shown how long-established language values and linguistic practices (i.e. the use of Castilian in Catalonia, standard English as a lingua franca, written Spanish over spoken Spanish or the use of minorized languages to create particular communicative effects) permeate new interactional environments. These longestablished language values and linguistic practices, in turn, (re)produce asymmetry among participants within the interaction, which further strengthens the imbalances of the current status quo. Furthermore, all the essays, to a greater or lesser extent, highlight the decisive role that Spanish as a colonial language plays in the interactions observed.

The works of this issue have heeded the advice of Cicourel (1996) that 'ecological validity' cannot be achieved solely by close analysis of recordings of interactions; it also requires broader ethnographic research that enables researchers to place a particular encounter in the context of texts, interactions and institutional practices. The authors have based their observations on a plethora of data: analyses of recorded naturally-occurring conversations, (non)participant observation, document analysis and, in some cases, interviews, in an effort to further substantiate and demonstrate the claims they make and to obtain an overall picture of the interaction.

So, while all the authors concur in gathering an array of data, they assign different values to the type of data collected and, in particular, to conversation between the participants of their studies. The essays by Codó and Garrido as well as by Moyer make use of document analysis and selected interviews between the researcher and some of the 
participants either to bring to the fore well-known asymmetries between conversation partners or to analyse the recorded conversation in terms of power differences. These two papers are mainly focused on the institutional dimension and on how 'speech events frame and are framed by informal (often implicit or tacit) organisational policies and routine work practices' (Cicourel 2002:3). Hence, what we are involved in is a 'task-oriented ethnography', which involves 'the systematic observation and recording in the workplace of routine and special verbal, nonverbal and paralinguistic activities, documents produced by those activities and the use of routine and special artefacts by personnel' (Cicourel 2002:3). Observations of organisational settings, interactions and language use, accompanied by ethnographic descriptions of the layout of institutions, their working arrangements and daily social interactions, and their verbal, nonverbal and paralinguistic communications are at the core of task-oriented ethnography (Cicourel 2000:115).

Prego Vázquez examines power asymmetries when lexicalised as a potential interpretative frame in the actual conversation between the participants. She thus focuses on the function of contextualisation cues, among other devices, in the construction of institutional talk and contends that this resource is mobilised by the consumer in an effort to reduce the service provider's power and, by the default, that of the only institution responsible for providing an essential service to consumers. Similarly, Gómez shows how the interpreter in gatekeeping interviews with an asylum seeker exerts power by simply discarding elements of the applicant's narrative or determining others to be irrelevant and, as a result, becomes, instead of the interviewing official, the one policing the gate. Thus Prego Vázquez's and Gómez's papers examine power asymmetries in the actual conversation in the light of the potential multi-functionality of given interactional resources and are then tied to political, social and economic power asymmetries as represented and given by the institutional setting itself (a PPP which enjoys the monopoly of an essential service; an immigration office that decides the fortunes of migrant workers). Their research agenda is less critically oriented and sits more comfortably with the kind of work carried out in interactional sociolinguistics, albeit with a commitment to the examination of inequalities as primarily evidenced in talk.

In line with Prego Vázquez and Gómez, Márquez Reiter’s paper focuses on the actual interaction between the conversational participants and is less focused on the institutional dimension. Márquez Reiter also examines power differences but only when these are made relevant in the actual conversation by the participants themselves. She then uses notes from observation, interviews and socio-demographic information to provide further support for the claims made on the basis of the conversation examined. Thus, while both Prego Vázquez and Márquez Reiter focus, to varying degrees, on the incidence of metacommunicative acts, Márquez Reiter finds their potential meaning in the actual conversation as demonstrated by lexicalised propositional content and not necessarily tied to ingrained power inequalities of the institutional setting examined. These three papers, then, also share a concern with the expression of power in interaction but Márquez Reiter's is underpinned by a more constructivist view of reality, one where the search for meaning and knowledge is principally found in talk-in-interaction, as constructed by the conversational participants themselves.

Overall the analyses go beyond the fine-grained scrutiny of language practices in service encounters, taking into account that the aim is not just to reveal routines and interactional patterns or to investigate the negotiation process that takes place in them. All 
the authors focus on how speakers employ linguistic resources (forms and practices) in order to build social differences and power relationships. The aim, rather, is to understand current linguistic practices in the context of colonial processes, globalisation and national and supranational ideologies and projects (Heller 1999, 2007). At the same time, the papers seek to discover how linguistic resources are allocated and how this allocation affects the construction of inequalities. However, the analyses are focused on different linguistic features and dimensions: from how linguistic resources are distributed within institutional practices to participants' linguistic choices in face-to-face or mediated encounters. Such differences are welcome in fostering debate and cross-fertilisation of sociodiscursive analytic angles. We, the editors, are aware that this is just a small step forward, but it is one we are proud of.

\section{Notes}

1 This concept combines Bourdieu's linguistic market theory with Foucault's view of the order of discourse. Other authors have also explored how social fields and spaces (in this case, the physical bounds of the classroom) organise and/or establish patterns of multilingualism. Blommaert, Collins and Slembrouck (2005) use the term 'regimes of language' and confer a constitutive and agentive role to the concept of space in this organisation.

2 One of the theoretical cornerstones of Bourdieu's sociology is the idea of society as a plurality of social fields. Forms of capital (economic, cultural and social) are the core factors defining positions and possibilities of the various actors in any field. Each social field has a profile of its own, depending on the proportionate importance within it of each of the forms of capital. The ways capitals are distributed within a field are trumps that define the access of users to field activities (Bourdieu 1984).

3 The origin of this correlation can be traced to a series of significant historical processes which brought about the creation of the modern State. Thus, although linguistic diversity is not a strange occurrence in our societies (none of the European countries is monolingual), it is also true that the deeply rooted association between language and State, born with the French Revolution-although it had already started to develop with the expansion of Castilian Spanish after the discovery of America-contributed to the creation of monolingual states. On how States have tried to fulfil the isomorphism of language, nation and state, see, among others, Barbour and Carmichael (2001) for Europe, Kamusella (2009) in the case of Central and Eastern Europe and Wright (2000) on the impact of language in nation state building in European integration.

\section{References}

Arminen, I. (2005) Institutional Interaction-Studies of Talk at Work. Ashgate: Aldershot.

Barbour, S. and Carmichael, C. (eds). (2001) Language and Nationalism in Europe. Oxford University Press.

Billig, M. (1995) Banal Nationalism. London: Sage. 
Blommaert, J. (2003) Commentary: A sociolinguistics of globalization. Journal of Sociolinguistics 7(4): 607-623.

Blommaert, J., Collins, J. and Slembrouck, S. (2005) Spaces of Multilingualism. Language and Communication 25: 197-216.

Bourdieu, P. (1984) Distinction: A Social Critique of the Judgment of Taste. Harvard University Press.

Bührig, K. and Meyer, B. (2004) Ad-hoc-interpreting and the achievement of communicative purposes in doctor-patient-communication. In J. House and J. Rehbein (eds) Multilingual Communication 43-62. Amsterdam: Benjamins.

Castells, M. (1996/2000) The Rise of the Network Society. Oxford and Malden, MA: Blackwell.

Cicourel, A.V. (1996) Ecological validity and 'white room effects': The interaction of cognitive and cultural models in the pragmatic analysis of elicited narratives from children. Pragmatics and Cognition 4(2): 221-264.

Cicourel, A.V. (2002) Organisation et communication en régime de surcharge cognitive [Discourse and organisational practices in the workplace: Coping with 'normal' task interruptions and 'cognitive overload]. Actes de la Recherche en Sciences Sociales 143: $3-17$.

Codó, E. (2008) Immigration and Bureaucratic Control. Language Practices in Public Administration. Berlin/New York: Mouton de Gruyter.

Codó, E., Dooly, M., Garrido, M.R., Moyer, M.G. and Ruíz L. (2007) Constructions of multilingualism and multimodality in institutional sites. Paper presented at the Sixth International Symposium on Bilingualism, 2 June, at the University of Hamburg, Germany.

Duchêne, A. and Heller, M. (in progress) Pride and Profit. Language in Late Capitalism.

Fitch, K. (1991) The interplay of linguistic universals and cultural knowledge in personal address: Colombian madre terms. Communication Monographs 58: 254-272.

García Borrego, I. (2007) Jóvenes Migrantes y Sociedades en Tránsito. Gobierno de Canarias. Dirección General de Juventud.

Goffman, E. (1979) Footing. Semiotica 25(1-2): 1-29.

Gumperz, J.J. (1982a) Discourse Strategies. Cambridge: Cambridge University Press.

Heller, M. (2002) Actors and discourses in the construction of hegemony. Pragmatics 13(1): 11-32.

Heller, M. (2003) Globalization, the new economy and the commodification of language and identity. Journal of Sociolinguistics 7(4): 473-492.

Kamusella, T. (2009) The Politics of Language and Nationalism in Modern Central Europe. Basingstoke: Palgrave.

Martín Rojo, L. (1997) Jargon. In J. Verschueren, J.O. Östman and J. Blommaert (eds) Handbook of Pragmatics (vol. 2) 2-19. Amsterdam: Benjamins. 
Martín Rojo, L. (2001) New developments in discourse analysis: Discourse as social practice. Folia Linguistica 35(1-2): 41-78.

Martín Rojo, L. (2010) Constructing Inequality in Multilingual Classrooms. Berlin: Mouton de Gruyter.

Márquez Reiter, R. and Placencia, M.E. (2004) Displaying closeness and respectful distance in Montevidean and Quiteño service encounters. In R. Márquez Reiter and M.E. Placencia (eds) Current Trends in the Pragmatics of Spanish 121-155. Amsterdam: John Benjamins.

Moreno Cabrera, J.C. (2008) El Nacionalismo Lingüístico. Análisis Crítico [Linguistic Nationalism. A Critical Analysis]. Barcelona: Península.

Moyer, M.G. (forthcoming) What Multilingualism? Agency and unintended consequences of multilingual practices in a Barcelona health clinic. Journal of Pragmatics.

Moyer, M.G. and Martín Rojo L. (2007) Language, migration and citizenship: New challenges in the regulation of bilingualism. In M. Heller (ed.) Bilingualism: A Social Approach 137-160. Palgrave: Macmillan.

Pujolar, J. (2007) Beyond the nation-state: International agencies as new sites of discourses on bilingualism. In M. Heller (ed.) Bilingualism: A Social Approach [page numbers]. Palgrave: Macmillan.

Wright, S. (2000) Community and Communication: The Role of Language in Nation State Building and European Integration. Cleveland: Multilingual Matters. 